Det må være rom for å gi en mer nyansert diagnosevurdering enn det en ren skjematisk avkrysning kan gi. Et elektronisk overføringssystem må også være lett å oppdatere, uavhengig av leverandør.

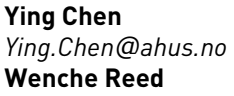

Ying Chen (f. 1960) er leder i Den norske patologforening og avdelingssjef ved Avdeling for patologi, Akershus universitetssykehus.

Ingen oppgitte interessekonflikter.

Wenche Reed (f. 1954) er leder av Forskningsseksjonen, Stab forskning. innovasjon og utdanning, Oslo universitetssykehus, nestleder i styret i Den norske patologforening og leder av foreningens forskningsutvalg. Ingen oppgitte interessekonflikter.

Tor-Arne Hanssen (f. 1967) er styremedlem i Den norske patologforening, leder av Kvalitetsutvalget i Den norske patologforening og utbyggingssjef ved Universitetssykehuset Nord Norge.

Ingen oppgitte interessekonflikter.

Litteratur

1. Bjugn R, Casati B, Haugland HK. Strukturert e-journal. Tidsskr Nor Legeforen 2014: 134: 431-3.

2. Den norske patologforening. Veileder i biopsibesvarelse av maligne svulster http://legeforeningen.no/PageFiles/40830/Veileder\%20i\%20biopsibesvarelser\% 20DNP\%202012.pdf (2.4.2014).

3. Hassell LA, Parwani AV, Weiss L et al. Challenges and opportunities in the adoption of College of American Pathologists checklists in electronic format: perspectives and experience of Reporting Pathology Protocols Project (RPP2) participant laboratories. Arch Pathol Lab Med 2010; 134: 1152-9.

\section{R. Bjugn og medarbeidere svarer:}

I vår kronikk påpekte vi at praktisk realisering av politiske overordnede mål er et komplekst samspill mellom ulike aktører i helsevesenet. Suksessen som Ontario har hatt med sitt prosjekt for strukturert patologirapportering ved kreft skyldes bl.a. at det medisinske fagmiljøet selv har tatt valg med hensyn til hvordan man bør bruke ressursene. Patologforeningen i Ontario fant det således mest hensiktsmessig å samarbeide med sine amerikanske kolleger om faglige retningslinjer fremfor å utvikle egne. Denne tankegangen om samarbeid mellom medisinske fagorganisasjoner i ulike land for å nå felles mål er tatt videre i International Collaboration on Cancer Reporting (1). Helsevesenet i Norge påvirkes av hva aktører i andre land, både i og utenfor Europa, gjør. Vi synes derfor samarbeid med andre alltid bør vurderes når man skal løse lokale utfordringer, spesielt i situasjoner hvor andre har lykkes.

Vi foreslo bruk av strukturerte maler utarbeidet av College of American Pathologists. Chen og kolleger betviler at «import av en amerikansk løsning» er veien å gå. For oss er egnethet for å løse en oppgave det viktigste, ikke hvor løsningen kommer fra. I en rekke andre sammenhenger bruker vi «amerikanske løsninger» med lokal tilpasning, for eksempel norsk versjon av tekstbehandlingssystem laget av Microsoft. Tilsvarende tror vi det kan være mer hensiktsmessig, både faglig og ressursmessig, å samarbeide med College of American Pathologists om å tilpasse deres strukturerte maler til norske forhold fremfor å utvikle alt selv. Samme vurdering gjorde også fagorganisasjoner og politiske myndigheter i Ontario.

Chen og kolleger henviser til en studie om implementering og bruk av elektroniske patologimaler i fire amerikanske delstater hvor erfaringene var både positive og negative, avhengig av hvilket ståsted man hadde (2). I sin oppsummering skriver imidlertid forfatterne at det bør stimuleres til økt bruk av slike sjekklister og strukturerte maler, og at det må være incentiver for alle involverte.

Vi er enige med Chen og kolleger om at kun «skjematisk avkryssing» ved bruk av strukturerte maler ikke er hensiktsmessig, og at det må være plass for både fritekst og andre innholdsmessige ele- menter. Gjennom å etablere generiske informasjonsmodeller og felles terminologi for patologibesvarelser (3), har for eksempel The Royal College of Pathologists of Australasia arbeidet forbilledlig i så måte. Vi tror igjen at erfaringer fra slikt grunnarbeid med stor nytte kan brukes av både Den norske patologforening og andre organisasjoner i Norge når det skal utarbeides nasjonale kodeverk og retningslinjer.

\section{Roger Bjugn}

rogbju@ous-hf.no

Bettina Casati

Hans Kristian Haugland

Litteratur

1. International Collaboration on Cancer Reporting. www.rcpa.edu.au/ Health-Care-Professionals/ICCR (28.4.2014).

2. Hassell LA Parwani AV Weiss L et al. Challenges and opportunities in the adoption of College of American Pathologists checklists in electronic format: perspectives and experience of Reporting Pathology Protocols Project (RPP2) participant laboratories. Arch Pathol Lab Med 2010; 134: 1152-9.

3. Pathology Terminology and Information Standardisation. www.rcpa.edu.au/ Library/Practising-Pathology/PTIS/APUTS-Downloads (28.4.2014).

\section{Re: Melankolikerne har hatt landsmøte}

Skulle ønske jeg kunne være med i MOLL, men jeg er vel for optimistisk, for alltid når noen sier: «Verre enn det er nå, kan det neppe bli», så svarer jeg: «Å, jo da!» (1).

\section{Marte Mellingsæter \\ cmelling@online.no}

Marte Mellingsæter (f. 1973) er lege ved Akershus universitetssykehus Ingen oppgitte interessekonflikter - om ikke medlemskapet i DUR (dystymi uten realitetsorientering) kommer i konflikt.

Litteratur

1. Nakken KO. Melankolikerne har hatt årsmøte. Tidsskr Nor Legeforen 2014; 134: 762

\section{Re: Bloggbok om alternativ behandling}

Jeg stiller meg litt undrende til at Tidsskriftet har valgt nettopp en akupunktør til å anmelde Gunnar Tjomlids bok (1). Det kan jo, med tanke på innholdet, ha vært vanskelig å skille det subjektive og det objektive for anmelderen, noe som jeg også synes preger teksten. Det virker som om anmelderen først og fremst er opptatt av, noe overbærende, å beskrive boken som en bagatell, heller enn å skildre spesifikt hvilke svakheter den måtte ha.

Jeg stusser også på den siste linjen «... jeg forstår at bloggeren innimellom sliter med prøve å fylle rollen som vitenskapsmann, og enda verre, som medisinsk behandler», da Gunnar Tjomlid aldri har forfektet noen rolle som vitenskapsmann, og langt mindre som medisinsk behandler.

\section{Henning Tveit \\ henning.tveit@sonans.no}

Henning Tveit (f. 1971) er lærer ved Sonans Utdanning.

Ingen oppgitte interessekonflikter

Litteratur

1. Norheim AJ. Bloggbok om alternativ behandling. Tidsskr Nor Legeforen 2014; 134: 744 